DOI: 10.12731/2077-1770-2020-5-178-192 УДК 811.111

\title{
КОММУНИКАТИВНЫЕ ИНФОРМАЦИОННЫЕ СТРАТЕГИИ ЦИФРОВОЙ ДИПЛОМАТИИ ВЕЛИКОБРИТАНИИ
}

Кауфова И.Б., Кауфова Л.А.

Цель. Авторы ставят иеелью выявление коммуникативных информационных стратегий иифровой дипломатии, которыми пользуется известный современный британский политик Б. Джонсон в рамках международных сочиальных сетей.

Метод и методология исследования. Основными методами исследования данной работы являются лингвистический, описательный и логико-семантический.

Результаты. Цифровая дипломатия использует определенные коммуникативные стратегии, среди которых информационные являются ключевыми. Они реализуются преимущественно посредством отбора определенной информации, детального развития информачии и замалчивания некоторых фактов. Использование сочиальных сетей допускает употребление специальных лексических средств, введенных в структуру текста с иелью скрытой манипуляиии.

Область применения результатов. Результаты исследования могут быть применены в области политической лингвистики, культурологи и политической лингвистики.

Ключевые слова: иифровая дипломатия; дипломатический дискурс; политический дискурс; Твиттер; информачионные стратегии; языковые средства; Великобритания; премьер-министр .

\section{COMMUNICATIVE INFORMATION STRATEGIES IN DIGINAL DIPLOMACY OF GREAT BRITAIN}

\section{Kaufova I.B., Kaufova L.A.}

Purpose. The article deals with analyzing communicative information strategies of digital diplomacy, used by a famous modern British politician B. Johnson on international social networks. 
Methodology. The linguistic, descriptive methods and the method of logic and semantic analysis are used as basic methods of the research.

Results. Digital diplomacy uses certain communication strategies, among which information strategies are crucial. They are implemented mainly by the selection of certain information, detailed development of information and suppression of some facts. Political messages shared on Twitter contain emotional language for the purpose of hidden manipulation.

Practical implications. Research results can be applied in political linguistics, cultural science and political science.

Keywords: digital diplomacy; diplomatic discourse; political discourse; Twitter; information strategies; language means; Great Britain; Prime Minister.

В эпоху глобализации и интенсивного развития информационно-коммуникационных технологий мир стал восприниматься как целостная система, глобальное информационное сообщество, которое оказывает мощное влияние практически на все сферы жизни государств и, как следствие, мировую политику. Появление социальных сетей является относительно новым явлением эпохи цифровых технологий. Их бурное развитие способствует изменениям в информационном пространстве и определяет трансформацию в политической сфере. Инструменты, которыми пользуется цифровая дипломатия, являются рычагами управления огромными массами людей, манипулирования общественным мнением в политических целях.

Политики, экспертные сообщества, внешнеполитические ведомства всех развитых стран с относительно недавнего времени стали обращать пристальное внимание на использование возможностей потенциала Интернета и его инструментов для удовлетворения внешних и внутренних нужд своей страны, укрепления ее репутации и позиций на международной арене. Информационная среда диктует новые правила игры, усложняет международную систему, расширяя список ее участников, форматы социально-политических событий, зачастую становясь фактором нестабильности и появления дополнительных угроз. 
В настоящее время существует несколько терминов, описывающих данное явление: «цифровая дипломатия», «сетевая дипломатия», «дипломатия Web 2.0», «Твиттер-дипломатия», «электронная дипломатия» и прочие. В силу отсутствия общепринятой концептуальной основы под данными терминами подразумеваются разные критерии определения. В данной статье мы пользуемся термином «цифровая дипломатия», под которым понимается широкое использование информационно-коммуникационных технологий, таких как новые медиа, социальные сети, блоги и им подобные медиаплощадки в Интернете в целях содействия государственным органам в осуществлении функций и коммуникаций, связанных с внешней политикой, включая рычаги влияния на зарубежную аудиторию. Сферами влияния цифровой дипломатии можно назвать присутствие в Интернете радио- и телепрограмм, рассылку информации через смартфоны, мониторинг дискуссий в блогах, странички политиков в социальных сетях и т.д. [11, с. 53]. Коммуникативные стратегии цифровой дипломатии представляют несомненный интерес для исследователей политического и дипломатического дискурса в различных областях: философии, политологии, правоведениии, международных отношениях, социологии, психолингвистике и лингвистике. Изучению данного направления посвящено немало работ таких исследователей как Д.Н. Баринов [1], Л.Г. Викулова [2], Е.И. Горошко [3], А.В. Жидков [4], С.А. Кулик [8], Н.В. Новиков [10], Э.Г. Меграбова [9], И.В. Сурма [11] и др.

Актуальность статьи обусловлена новыми тенденциями современной лингвистики, изучающей коммуникативные и прагматические аспекты языка, неуклонно растущей ролью цифровых коммуникативных практик в современной политике, а также недостаточной разработанностью коммуникативных стратегий цифровой дипломатии в современном британском политическом и дипломатическом дискурсе.

Научная новизна работы обусловлена тем, что в ней впервые уточняется набор коммуникативных информационных стратегий, которые используют в своих выступлениях известные британские 
политики в рамках социальных сетей, выявляются способы создания коммуникативного пространства цифровой дипломатии с помощью применения информационно-коммуникативных технологий для решения коммуникативных задач в политике.

Целью статьи является выявление коммуникативных информационных стратегий цифровой дипломатии, которыми пользуется известный современный британский политик Б. Джонсон в рамках международных социальных сетей.

В современных условиях политики и дипломаты обязаны использовать Интернет в целях получения информации, определения ключевых персон влияния, зарубежного и отечественного общественного мнения, распространения идей в своей стране и за рубежом, наблюдения за выборами, определения влиятельных пользователей Интернета, организации форумов и даже таких серьезных мероприятий, как революция. Влиятельные интернет-платформы Facebook и Twitter предоставляют политикам и дипломатам прямой доступ к гражданам внутри страны и за ее пределами, где они искусно используют сочетание экономических, дипломатических, политических и других мер в целях применения цифровой дипломатии как эффективного инструмента управления массами.

Великобритания считается одним из флагманов западного мира, и в силу этого, политические события, происходящие в стране, отражаются на развитии всей Европы. Британская элита все еще интенсивно использует систему традиционных СМИ, одновременно учитывая предпочтения населения и осуществляя динамику взаимодействия с публикой в социальных сетях. Необходимо отметить, что в 2020 г., по данным портала Influencer Marketing Hub [13], количество пользователей социальных сетей в мире достигло 3.8 млрд., что составляет чуть меньше половины всего населения планеты. В Великобритании самыми востребованными социальными сетями являются: Facebook 44 млн. пользователей, Twitter - 13,7 млн. подписчиков, YouTube - 39 млн. человек, LinkedIn - 27,5 млн., Instagram - 24,4 млн. и т.д.

Социальные сети, особенно международные, дают возможность создавать профиль отдельного человека, группы или даже полити- 
ческой партии и государственной организации, предоставив при этом информацию о себе, распространять контент, взаимодействовать с пользователями, отслеживать ленту новостей, активность других пользователей. Пользователь имеет право прикреплять фотографии, видео, помещать опросы, приводить ссылки.

Объектом исследования был выбран блог Твиттер (Twitter) известного британского политика, действующего премьер-министра Великобритании Б. Джонсона. Как известно, Твиттер - это информационно-коммуникативная сеть, работающая в режиме реального времени, что позволяет пользователям отслеживать новейшие события, в том числе, политические. Политики выбирают данную социальную сеть для общения с публикой благодаря следующим факторам: 1) быстрота создания аккаунта и высокая степень оперативности; 2) общение в синхронном режиме; 3) краткость и точность изложения, при котором максимальный объем в 280 символов придает каждому сообщению высокую степень информативности и значимости; 4) простой способ «достучаться» до каждого пользователя, проведя беседу «с глазу на глаз»; 6) возможность проявить себя не только как политического деятеля, но и обычного человека, которому доверили представлять интересы всей нации. Есть еще один фактор: политик с готовностью проявляет свои личностные качества и характеристики: красноречие, чувство юмора, степень образованности, что может позитивно отразиться на его имидже и целях, которые он преследует.

По мнению исследователей, Твиттеру свойственны функции, которые являются незаменимыми для политика высокого ранга в плане завоевания авторитета и поддержания связи с аудиторией: информационная, психологическая, коммуникативная, оценочная, воздействующая и функция самопрезентации. Сообщения в блоге часто носят поликодовый характер, включая фотоснимки и видео, отражающие суть и хронологию происходящего. Разумеется, политические коммуникации в социальных сетях существуют не изолированно, они встроены в «глобальный дискурс», который формируется в медиаполе [1, с. 761]. 
Главным оружием цифровой дипломатии как коммуникативного пространства, являются различные коммуникативные стратегии. Мы присоединяемся к мнению ряда исследователей и придерживаемся точки зрения, что коммуникативная стратегия - это комплекс речевых действий, направленных на достижение коммуникативной цели [5, с. 54]. В нашем исследовании мы остановимся на информационных стратегиях цифровой дипломатии на материале микроблога Твиттер Б. Джонсона @BorisJohnson Материалом исследования послужила личная страничка Б. Джонсона за период с конца марта до середины июля 2020 года.

Оформление блога Бориса Джонсона выглядит вполне традиционно и включает обязательные элементы: 1) фоновое изображение (фото обложки); 2) профиль пользователя, включая его должность, звание; 3) дату открытия блога; 4) ленту записей и страницу отдельной записи блога; 5) количество подписчиков; 6) актуальные призывы и лозунги.

Информационные стратегии, несомненно, являются ключевыми в цифровой дипломатии. Известно, что они реализуются в таких формах, как:

1) отбор определенной информации;

2) детальное развитие информации;

3) замалчивание некоторых фактов (стратегия умолчания) [9, с. 20].

Предполагается, что информирование, особенно сообщения о политических событиях, должно носить объективный характер. Б. Джонсон, как опытный политик, умело отбирает темы для микроблога. Основной целью коммуникативного присутствия политика в социальных сетях является информирование пользователей об основных внешних и внутренних политических событиях, непосредственным участником или инициатором которых является данный политический деятель. Именно поэтому дискурс Б. Джонсона отличает информационная направленность преимущественно на события страны. Например, в нем всегда присутствует информирование о стратегии правительства, пресс-конференциях, рабочих встречах: 


\section{1) Jul 1}

We're investing an additional £14bn in schools and launching a ten year school building programme, so that every child can receive a fantastic education and opportunities to succeed [12].

2) Jul 17

Today I have announced the next chapter in our coronavirus recovery strategy.

Read my full statement here: https://gov.uk/government/speeches/ pm-statement-on-coronavirus-17-july-2020 [Там же].

Б. Джонсон использует данный жанр виртуального пространства, новый вид коммуникации, предусматривающий общение миллионов коммуникантов одновременно в целях информирования аудитории о политических предпочтениях правительства, используя бинарную оппозицию «свой-чужой» [6; 7]. Под «своими» понимаются страны-союзники, которых Борис Джонсон неустанно поздравляет со всеми знаменательными событиями. Например:

1) Jul 13

Congratulations to@AndrzejDuda on your re-election as President of Poland. The UK and Poland have a long, shared history and friendship in Europe, NATO and elsewhere. I look forward to that continuing as we face the challenges and opportunities ahead [Там же].

2) Jun 26

Congratulations to Ireland Flag of Ireland on forming a new Government and to@MichealMartinTD on becoming Taoiseach. Ireland is our closest neighbour, good friend and ally on issues such as climate change, the global fight against Covid-19 and our shared values on human rights and democracy [Там же].

3) Jun 17

I'm proud to call the United Kingdom a friend of New Zealand, and am thrilled that we now have the opportunity to strengthen our alliance by negotiating a new free trade agreement [Там же].

Иногда поздравление даже представлено на языке той страны, к которой оно обращено, как в случае с Э. Макроном, президентом Франции. Известно, что Б. Джонсон принимал у себя французско- 
го президента, чтобы почтить память бойцов французского сопротивления. 80 лет назад Шарль де Голль выступил по французской службе Би-би-си со знаменитой речью, в которой призвал сограждан оказать сопротивление нацистской Германии.

1) Jun 18

TodayIhosted@EmmanuelMacronat@10DowningStree for the 80th anniversary of General Charles de Gaulle's Appeal of 18 June. We will never forget the sacrifices that were made for our freedom.

Our countries will forever be neighbours and friends, united by our shared values [Там же].

2) Jun 18

Aujourd'hui,j'ai accueilli@EmmanuelMacronà@10DowningStreet pour le 80e anniversaire de l'appel du général Charles de Gaulle du 18 juin. Nous n'oublierons jamais les sacrifices faits pour notre liberté.

Nos pays seront à jamais voisins et amis, unis par nos valeurs communes [Там же].

Таким образом, Б. Джонсон использует свой блог в качестве шагов на пути к более тесному взаимодействию и сближению со своими союзниками из стран Европы и всего мира.

К «чужим» чаще всего относятся некоторые страны (чаще всего Россия), террористы и лица, нарушающие общественный порядок: Jun 21

I'm appalled and sickened that people should lose their lives in this way. Our thoughts are with the families and friends of the victims.

Thank you to Thames Valley Police for their bravery in tackling the suspect [Там же].

Организация информационного потока в Твиттере оказывает ключевое воздействие на аудиторию. В силу этого исключительно важно предоставлять детальное развитие информации. Для реализации данной стратегии в своем микроблоге премьер-министр Великобритании Б. Джонсон решил последовать примеру американского президента Д. Трампа и ежедневно проводить пресс-конференции, которые будут транслироваться по телевидению. Это можно считать крутым переворотом во взаимоотношениях прави- 
тельства с британской прессой и страной в целом. Новация авторства Джонсона рассчитана на большую открытость. Цель новой инициативы Джонсона - сделать для британцев максимально прозрачной работу своего правительства. Например:

\section{Jul 11}

It was fantastic to be back answering your questions at \#PeoplesPMQs yesterday [Там же].

Другой пример детального развития информации - освещение на страничке Твиттера Б. Джонсона всей истории развития пандемии и ежедневных мер, которые принимает Великобритания по борьбе распространением коронавируса. Например:

\section{Jul 17}

Today I announced the next chapter in our coronavirus recovery strategy.

Read my full statement here: ttps://www.gov.uk/government/speeches/ pm-statement-on-coronavirus-17-july-2020 [Там же].

Сам премьер-министр является пострадавшим от пандемии, лично перенеся заболевание. Он регулярно благодарит медков за их преданность своему делу и нации:

\section{Jul 14}

Yesterday I spoke to the incredible staff at the London Ambulance Service, who work so hard to save lives.

Thank you to all the ambulance staff across the UK, for all of your hard work and support throughout this pandemic [Там же].

Отличительной чертой информационного дискурса Твиттера Б. Джонсона является личностная оценка политика, выраженная эмотивными языковыми средствами, как правило, в форме экспрессивных прилагательных, наречий и глагольных форм: incredible staff; hard work and support; a fantastic education; I'm proud and thrilled; I'm appalled and sickened и др.

Важно отметить, что в цифровой дипломатии использование приемов манипуляции наблюдается гораздо реже, чем в традиционных СМИ. Это связано с тем, что дискурс цифровой дипломатии в большей степени, чем дискурс СМИ характеризуется намерением 
скрыть манипулирование под информированием, что можно объяснить желанием политиков и дипломатов остаться в рамках своего профессионального дискурса, предполагающего отсутствие категоричности суждений. Это значит, что манипулирование мнением адресата имеет завуалированный характер, не только с помощью экспрессивного языка, но и посредством предоставления неполной информацию и умалчивания неугодных фактов.

Британский премьер-министр освещает в своем блоге все важные даты, связанные с историей страны и Европы. Например:

1) May 29

On International Day of UN Peacekeepers, I want to pay my tribute to the Blue Helmets and many others who do so much to bring peace in areas of the world torn apart by conflict [Там же].

2) $\mathrm{Jul} 10$

80 years ago today our brave airmen took to the skies to defend this country. It was these few, as Churchill said, who turned the tide of the war and defended these islands from fascism and tyranny.

Today we remember their bravery and sacrifice. \#BattleOfBritain [Там же].

3) May 7

Tonight I lit a candle by the grave of the Unknown Warrior in Westminster Abbey in remembrance of those who gave their lives for the cause of freedom in the Second World War, which ended in Europe 75 years ago tomorrow [Там же].

Однако политик умалчивает, какую роль в победе над фашизмом сыграли другие страны, без участия которых не было бы победы во Второй мировой войне. В данном факте усматривается применение стратегии умолчания, которая является неотьемлемой составляющей информационных стратегий.

Итак, цифровая дипломатия использует определенные коммуникативные стратеги, среди которых ключевыми можно считать информационные. Они реализуются преимущественно посредством отбора определенной информации; детального развития информации и замалчивания некоторых фактов (стратегия умолчания). 
Хотя информирование предполагает беспристрастное освещение определенных политических событий, использование социальных сетей допускает употребление специальных лексических средств, введенных в структуру текста с целью скрытой манипуляции. Дискурс политика в социальных сетях приближается к устной форме общения и нередко отличается использованием особых приемов речевой выразительности - эмоциональной лексики. Степень выраженности авторского начала в политическом Твиттере довольно высока, что позволяет выявить индивидуальные характеристики политика и способствовать росту его влияния на адресата.

\section{Список литературы}

1. Баринов Д.Н. Политический дискурс в социальных медиа: специфика производства и факторы эффективности // Политика и Общество. 2016. № 6 (138). С. 755-764.

2. Викулова Л.Г., Макарова И.В., Новиков Н.В. Институциональный дискурс цифровой дипломатии: новые коммуникативные практики // Вестник ВолГУ. Серия 2: Языкознание. 2016. №3. С. 54-65. URL: https://cyberleninka.ru/article/n/institutsionalnyy-diskurs-tsifrovoydiplomatii-novye-kommunikativnye-praktiki (дата обращения: 21.07.2020).

3. Горошко Е.И., Полякова Т.Л. Политический твиттинг как новый жанр интернет-коммуникации // Вопросы психолингвистики. 2014. №19. C.92-103. URL: https://cyberleninka.ru/article/n/politicheskiytvitting-kak-novyy-zhanr-internet-kommunikatsii (дата обращения: 21.07.2020).

4. Жидков А.В. Социальные сети как фактор изменений в политической сфере общественной жизни (на примере Великобритании) // Общество: политика, экономика, право. 2018. №3. C. 35-38. URL: https://cyberleninka.ru/article/n/sotsialnye-seti-kak-faktor-izmeneniyv-politicheskoy-sfere-obschestvennoy-zhizni-na-primere-velikobritanii (дата обращения: 21.07.2020).

5. Иссерс О.С. Коммуникативные стратегии и тактики русской речи. М.: URSS; ЛКИ, 2008. 288 c. 
6. Кауфова И.Б., Кауфова Л.А. Образ врага в британском политическом дискурсе // Язык и культура в эпоху интеграции научного знания и профессионализации образования: Материалы II международной научно-практической конференции. Пятигорск: ПГУ, 2018. С. 54-61.

7. Кауфова И.Б., Кауфова Л.А. Оппозиция «свой-чужой» в британском политическом дискурсе // Университетские чтения-2019. Материалы научно-методических чтений ПГУ. Часть II. Пятигорск: ПГУ, 2019. C. 51-57.

8. Кулик С.А. Электронная дипломатия. Начало. Аналитический доклад. URL: http://www.ifap.ru/library/book532.pdf

9. Меграбова Э.Г. Образ России в дискурсе журнала Newsweek / Языковая репрезентация образа России в публицистическом дискурсе стран Запада и Востока: колл. монография / отв. ред. Э.Г. Меграбова. Владивосток: Изд-во Дальневост. ун-та, 2009. С. 7-46.

10. Новиков Н.В. Коммуникативные стратегии цифровой дипломатии: автореф. дис. ... канд. фил. Наук. М., 2017. 25 с.

11. Сурма И.В. Цифровая дипломатия в дискурсе глобальной политики // Вестник МГИМО. 2014. №6 (39). С. 53-60. URL: https:// cyberleninka.ru/article/n/tsifrovaya-diplomatiya-v-diskurse-globalnoypolitiki (дата обращения: 21.07.2020).

12.Boris Johnson \#StayAlert@BorisJohnson. URL: https://twitter.com/ BorisJohnson (дата обращения: 21.07.2020)

13. Social Media Trends for 2020 and Beyond. URL: https://influencermarketinghub.com/social-media-trends/ (дата обращения: 21.07.2020).

\section{References}

1. Barinov D.N. Politicheskij diskurs v social'nyh media: specifika proizvodstva i faktory effektivnosti [Political discourse in social media: production specifics and efficiency factors]. Politika i Obshchestvo. 2016. No 6 (138), pp. 755-764.

2. Vikulova L.G., Makarova I.V., Novikov N.V. Institucional'nyj diskurs cifrovoj diplomatii: novye kommunikativnye praktiki [Institutional discourse of digital diplomacy: new communication practices]. Vestnik 
VolGU. Seriya 2: Yazykoznanie. 2016. No 3, pp. 54-65. URL: https:// cyberleninka.ru/article/n/institutsionalnyy-diskurs-tsifrovoy-diplomatii-novye-kommunikativnye-praktiki.

3. Goroshko E.I., Polyakova T.L. Politicheskij tvitting kak novyj zhanr internet-kommunikacii [Political twitting as a new genre of online communication]. Voprosy psiholingvistiki. 2014. No 19, pp. 92-103. URL: https:// cyberleninka.ru/article/n/politicheskiy-tvitting-kak-novyy-zhanr-internet-kommunikatsii.

4. Zhidkov A.V. Social'nye seti kak faktor izmenenij v politicheskoj sfere obshchestvennoj zhizni (na primere Velikobritanii) [Social networks as a factor of changes in the political sphere of public life (on the example of Great Britain)]. Obshchestvo: politika, ekonomika, pravo. 2018. No 3, pp. 35-38. URL: https://cyberleninka.ru/article/n/sotsialnye-seti-kak-faktor-izmeneniy-v-politicheskoy-sfere-obschestvennoy-zhizni-na-primere-velikobritanii

5. Issers O.S. Kommunikativnye strategii i taktiki russkoj rechi [Communicative strategies and tactics of Russian speech]. Moscow: URSS; LKI, 2008. 288 p.

6. Kaufova I.B., Kaufova L.A. Obraz vraga v britanskom politicheskom diskurse [The image of the enemy in British political discourse]. Yazyk i kul'tura $v$ epohu integracii nauchnogo znaniya i professionalizacii obrazovaniya: Materialy II mezhdunarodnoj nauchno-prakticheskoj konferencii [Language and culture in the era of the integration of scientific knowledge and professionalization of education: Materials of the II International Scientific and Practical Conference]. Pyatigorsk: PGU, 2018, pp. 54-61.

7. Kaufova I.B., Kaufova L.A. Oppoziciya «svoj-chuzhoj» v britanskom politicheskom diskurse [Friend or foe opposition in British political discourse]. Universitetskie chteniya-2019. Materialy nauchno-metodicheskih chtenij PGU [University Readings-2019. Materials of scientific and methodological readings of PSU]. Part II. Pyatigorsk: PGU, 2019, pp. 51-57.

8. Kulik S.A. Elektronnaya diplomatiya. Nachalo. Analiticheskij doklad [Electronic diplomacy. Start. Analytical report]. URL: http://www.ifap. ru/library/book532.pdf 
9. Megrabova E.G. Obraz Rossii v diskurse zhurnala Newsweek [The image of Russia in the Newsweek magazine discourse]. Yazykovaya reprezentaciya obraza Rossii v publicisticheskom diskurse stran Zapada i Vostoka: koll. monografiya [Linguistic Representation of the Image of Russia in the Publicistic Discourse of the West and East: Coll. monograph]. Vladivostok: Izd-vo Dal'nevost. un-ta, 2009, pp. 7-46.

10. Novikov N.V. Kommunikativnye strategii cifrovoj diplomatii [Communication strategies of digital diplomacy]: avtoref. dis. ... kand. fil. Nauk. Moscow, 2017. 25 p.

11. Surma I.V. Cifrovaya diplomatiya v diskurse global'noj politiki [Digital diplomacy in the global politics discourse]. Vestnik MGIMO. 2014. №6 (39), pp. 53-60. URL: https://cyberleninka.ru/article/n/tsifrovaya-diplomatiya-v-diskurse-globalnoy-politiki

12.Boris Johnson \#StayAlert@BorisJohnson. URL: https://twitter.com/ BorisJohnson

13. Social Media Trends for 2020 and Beyond. URL: https://influencermarketinghub.com/social-media-trends/

\section{ДАННЫЕ ОБ АВТОРАХ}

Кауфова Инесса Беталовна, доцент кафедры теоретической лингвистики и практики межкультурного общения, кандидат филологических наук

Пятигорский государственный университет

Проспект Калинина,9, г. Пятигорск, 357500, Российская Федераиия

ikaufova@yandex.ru

Кауфова Лола Аслановна, доцент кафедры экспериментальной лингвистики и межкультурной компетенции, кандидат филологических наук

Пятигорский государственный университет

Проспект Калинина,9, г. Пятигорск, 357500, Российская Федерачия

lkaufova@yandex.ru 


\section{DATA ABOUT THE AUTHORS}

Kaufova Inessa Betalovna, Associate Professor, Chair of Theoretic Linguistics and Intercultural Communication Practice, Ph.D. in Philology

Pyatigorsk State University

9, Prospekt Kalinina, Pyatigorsk, 357500, Russian Federation ikaufova@yandex.ru

SPIN-code: 4124-4408

ORCID: 0000-0001-7079-5185

Kaufova Lola Aslanovna, Associate Professor, Chair of Experimental Linguistics and Intercultural Competence, Ph.D. in Philology Pyatigorsk State University

9, Prospekt Kalinina, Pyatigorsk, 357500, Russian Federation lkaufova@yandex.ru

SPIN-code: 9901-7238

ORCID: 0000-0002-0967-6408

ResearcherID: N-6914-2018 